\title{
Cost-effectiveness Analysis on Advanced Cervical Carcinoma Patients at Dr Mohammad Hoesin General Hospital Palembang, South Sumatra, Indonesia
}

\author{
${ }_{1,2}$ Rizal Sanif, ${ }^{1}$ Wahyu Sulistiadi, ${ }^{2}$ Heriadi Manan, ${ }^{3}$ Rachmat Hidayat
}

\begin{abstract}
Introduction: The management of advanced cervical carcinoma still faces many obstacles in developing countries like Indonesia, and this has an impact on the efficacy of treatment and delays in treatment.
\end{abstract}

Objective: To compare the cost-effectiveness on advanced cervical carcinoma management between among patients treated with fully dosed chemotherapy once every in three weeks, and chemoradiation combination therapy in divided doses chemotherapy with radiation every week.

Methods: A retrospective study has been done from January to December 2014 at Mohammad Hoesin, General Hospital in Palembang. There were 105 patients newly diagnosed with advanced cervical carcinoma who fulfilled the criteria inclusion and divided into two groups; 66 patients were in the chemotherapy group and 39 patients were in the chemoradiation group. The total cost from diagnosis to treatment was analyzed by using activity-based costing (ABC) and cost-effectiveness ratio (CER) methods between chemotherapy and chemoradiation.

Result: This study showed that there were $64.76 \%$ of patients revealed a positive reaction to the chemoradiation and $57.57 \%$ to the chemotherapy. These differences wsere caused by the price of medical devices (62.48 \% for chemotherapy, $67.6628 \%$ for chemoradiation). On the other hand, the operational cost for chemotherapy was cheaper than of chemoradiation, 1, 502, 444, 446 IDR and 1, 591, 510, 404 IDR, respectively. The maintenance cost of chemotherapy was lower than the maintenance cost of chemoradiation. The total budget of chemotherapy for cervical carcinoma management $(43,345,805)$ was cheaper than of the total budget of chemoradiation therapy $(80,644,767)$. The CER for chemoradiation is lower than the CER for chemotherapy in terms of complete, partial or progressive clinical responses.

Conclusion: It can be concluded that the use of chemoradiation modality was more effective than the use of chemotherapy.

\footnotetext{
${ }^{1}$ Magister, ${ }^{2}$ Consultant, ${ }^{3}$ Staff

${ }^{1}$ Respati University of Hospital Administration, Jakarta, Indonesia ${ }^{2}$ Department of Obstetrics and Gynecology, Dr M Hoesin Hospital, Faculty of Medical, Sriwijaya University, Palembang, South Sumatra, Indonesia

${ }^{3}$ Department of Biomolecular, Faculty of Medicine, Universitas Sriwijaya, Palembang, South Sumatra, Indonesia

Corresponding Author: Rizal Sanif, Magister, Respati University of Hospital Administration, Jakarta, Indonesia; Department of Obstetrics and Gynecology, Dr M Hoesin Hospital, Faculty of Medical, Sriwijaya University, Palembang, South Sumatra, Indonesia, Phone: 0812786 4246, e-mail: rizalsanif @yahoo.com
}

Keywords: Advanced cervical carcinoma, Chemotherapy, Chemoradiation, Cost-effectiveness analysis.

How to cite this article: Sanif R, Sulistiadi W, Manan $H$, Hidayat R. Cost-effectiveness Analysis on Advanced Cervical Carcinoma Patients at Dr Mohammad Hoesin General Hospital Palembang, South Sumatra, Indonesia. J South Asian Feder Obst Gynae 2018;10(Suppl 1):316-320.

Source of support: Nil

Conflict of interest: None

Date of received: 24 January 2018

Date of acceptance: 17 June 2018

Date of publication: July 2019

\section{INTRODUCTION}

The facilities and modalities needed in managing and treating patients with carcinoma are terribly complex, particularly for cervical carcinoma. Not only medicine and medication facilities but also chemotherapy and radiotherapy modalities play an important role in achieving the optimum treatment. Unfortunately, those two kinds of facilities are limited in developing country. A recent report from the World Health Organization, around 528,000 new cases of cervical carcinoma are found every year and it is the top fourth highest rate of cancer after breast, colorectal and lung cancers in the developing country. Cervical carcinoma is also the top fourth causal rank of women death by cancer $(266,000$ mortality cases in 2012) around the world (70\% of deaths comes from a developing country). In 2007, the total cervical carcinoma patients are just around 7.9 , and $72 \%$ of them are from the developing country. It is projected that the human death caused by cancer will gradually increase and estimated around 12 million deaths in 2030 if only no adequate intervention created. ${ }^{1}$

In Indonesia, the prevalence of cervical carcinoma is very high, after cervical uteri cancer and breast cancer. Cervical carcinoma is highly interfered women's life either in sort of humanity, economic, or social aspects. Generally, Indonesian cervical carcinoma patients who are seeking an examination and treatment will be diagnosed as advanced cervical carcinoma. The incidence of cervical carcinoma in Indonesia is unknown, but it is estimated that around 180,000 new cases and the cases 
are inclining every year while the mortality cases estimated is just about $75 \%$ within the first year by the time when patients have firstly been diagnosed as cervical carcinoma. The death is widely correlated with invasive cervical carcinoma and evenly the terminal stage at first time diagnosed. ${ }^{2-5}$

It has been numerous obstacles in managing of cervical carcinoma related to facilities and modalities definitely affected by the budget, particularly in the advanced cervical carcinoma. Primarily, chemoradiation is the standard modality to treat the advanced cervical carcinoma. In fact, Indonesia is lacking in the external and internal radiation facilities then there has been a long and numerous queues for cervical carcinoma patients to get radiation treatment approximately within three to twelve months of waiting. Because of that, in the waiting period, cervical carcinoma patients sometimes will be given the chemotherapy, but this particular activity is still questioned for its effectiveness. While at Dr M Hoesin General Hospital, Palembang, the standard operation procedure for radiotherapy is external radiation with cobalt 60 and brachytherapy for internal radiation must be referred to the central hospital in Jakarta or will be given the external radiation. Unfortunately, the radiotherapy device in Dr M Hoesin Palembang General Hospital always breaks down and it takes a long time to fix the device in order to find out the new source of radiotherapy device.

In terms of lacking facilities, the option for treating advanced cervical carcinoma patients at Dr M Hoesin General Hospital, Palembang is influenced by many factors such as radiotherapy timeline, availability of chemotherapy drugs patients, characteristics and doctor in charge. Through economic evaluation, it will give us the best alternative which shows advantages in cost and effectiveness. ${ }^{6,7}$ Sorenson et al. in his research stated the importance of the organization of potential devices and nursing care availability in the hospital. He also stated that comparing the economic evaluation is also crucial. ${ }^{8}$

This study aimed was to compare the cost-effectiveness from two strategy management of advanced cervical carcinoma among patients who treated with full dosed chemotherapy once every three weeks versus chemoradiation combination therapy in divided doses chemotherapy with radiation every week at Dr M Hoesin General Hospital, Palembang.

\section{METHODS}

A retrospective study through economic evaluation of advanced cervical carcinoma management between patients with chemotherapy and chemoradiation therapy has been conducted at Dr M Hoesin General Hospital, Palembang. The populations of the study were all cervical carcinoma patients who treated in gynecology department and the samples of study are patients with advanced cervical carcinoma from January to December 2014, who met the inclusion criteria: Patients were diagnosed with advanced cervical carcinoma and treated at Dr M Hoesin General Hospital, Palembang. They have been advanced cervical carcinoma management by undergoing the carboplatin-paclitaxel chemotherapy in full dosed or combination dosed carboplatin chemotherapy-paclitaxel in split dosed every week with radiotherapy.

The protocol study has been approved by the Ethics Committee of Medical Faculty, Sriwijaya University (321/kptfkrsmh/2016). Data collection was carried out by writing all the activities related to variables which are being searched in this study. The data could be divided into secondary data through many sources such as patient's medical record in Obstetric and Gynecology emergency ward, inpatient record, pharmacy, radiology and radiotherapy, pathology anatomy and any other related departments. The confidentiality of all subject identity was guaranteed.

\section{Data Analysis}

The budget was counted by determining the budgets component from each of therapy such as investment, operational, and maintenance budgets. The price of the drug uses the price that engaged in the option of the medication while the budget for radiation is counted from the fare that has been determined by the hospital. Investment budget consists of building, bed, medical equipment, and nonmedical equipment. This budget could be counted through annualized investment cost (AIC). The operational budget consists of medical equipment budget and medical material, the medical and nonmedical salary of the employee, additional expenses such as stationary, electricity and water. Maintenance budget consists of medical and nonmedical equipment maintenance budget.

The total budget of each alternative could be collected by adding all the three kinds of the budget (operational, maintenance and investment). Output analysis or effectiveness of each alternative for advanced cervical carcinoma therapy is calculated through the sum of patients treated by two kinds of alternative namely carboplatinpaclitaxel chemotherapy and combined plaoxin chemotherapy each week with radiation. Then, analyzing the budgets and effectiveness uses cost-effectiveness ratio (CER) for each alternative. The ratio value means the comparison between total budget which has to be spent and output total of each alternative modality. After that, it will be analyzed for its effectiveness (cost-effectiveness analysis/CEA). If the ratio of CER is low, then it is the most efficient and effective modality. ${ }^{9}$ 


\section{RESULT}

The total population of the research was 274,330 outpatients during the period of the study, 5121 of them were gynecologic outpatients, 50,430 gynecologic inward patients, 6,728 obstetric inward patients, 744,744 having laboratory checked, 6,598 radiology checked, 3,204 chemotherapy, and 10,962 pathology anatomy examination. From January to December 2014, there were 188 total patients suffered from cervical carcinoma, $172(91.49 \%)$ of them taken therapy for stage II "B: to the fourth stage of advanced cervical carcinoma. During the management period, several modalities were applied such as chemotherapy, radiation, and chemoradiation. Seventy-eight $(41.49 \%)$ patients who underwent the chemotherapy treatment while 12 were excluded and 66 patients completed the chemotherapy scheduled. Forty-one (21.81\%) patients who underwent the radiotherapy treatment and 2 were excluded because of loss of complete treatment. In the end, only 39 patients reached the final analysis proses of the study. The samples of this study were 105 patients $(66.68 \%)$ treated with chemoradiation and chemotherapy.

The assessment of therapy output was done in 3 months after the therapy. It was found out that a higher number of patients who had a complete response was for chemoradiation than that of chemotherapy, namely $76.92 \%$ patients for chemoradiation and $57.57 \%$ for chemotherapy. Partial response was found in $27.27 \%$ patients with chemoradiation and $22.86 \%$ patients with chemotherapy. No response (stable disease) patients were around $13.64 \%$ patients with chemotherapy meanwhile progressive responses were just $1.52 \%$ and $3.81 \%$ for chemoradiation and chemotherapy patients, respectively.

Patient's distribution according to the cancer cell response of the complete chemoradiation or chemotherapy were 68 patients $(64.76 \%)$ and 13 patients $(12.38 \%)$ with no response and progressive state. Scandurra et al. stated that three cyclus of paclitaxel, iphosphamid, and cisplatin chemotherapy drugs would give complete response for $23 \%$ patients, the partial response for $61 \%$ patients, no response for $13 \%$ patients, and progressive response for $2 \%$ patients. ${ }^{10}$ Mise, et al. in his research got $100 \%$ complete response after giving concomitant chemobrachitherapy in advanced cervical carcinoma patients. ${ }^{11}$ In the end, all the cost from three components such as investment, operational and maintenance budgets which engaged in advanced cervical carcinoma management both chemoradiation and chemotherapy were calculated separately.

In Table 1 , it clearly showed that the total budget of chemotherapy is lower than the total budget of chemoradiation for 1,647,140,590 IDR and 2,419,343,010 IDR respectively. The budget for patients with partial response could not be assessed because no chemoradiation patient gives a response. Meanwhile, the progressive response
Table 1: Total budget for treating advance cervical carcinoma according to clinical response inward patients at Dr M Hoesin General Hospital, Palembang in 2014

\begin{tabular}{|c|c|c|c|}
\hline No & Response therapy & Chemotherapy & Chemoradiation \\
\hline \multirow[t]{4}{*}{ I } & Complete & & \\
\hline & Total budget & 2.860 .798 .361 & 3.145 .145 .914 \\
\hline & Clinical response & 38 & 30 \\
\hline & $\begin{array}{l}\text { Total budget according } \\
\text { to clinical response }\end{array}$ & 1.647 .140 .590 & 2.419 .343 .010 \\
\hline \multirow[t]{4}{*}{ II } & Partial & & \\
\hline & Total budget & 2.860 .798 .361 & 3.145 .145 .914 \\
\hline & Clinical response & 18 & 6 \\
\hline & $\begin{array}{l}\text { Total budget according } \\
\text { to clinical response }\end{array}$ & 780.224 .490 & 483.868 .602 \\
\hline \multirow[t]{4}{*}{ III } & No response & & \\
\hline & Total budget & 2.860 .798 .361 & 3.145 .145 .914 \\
\hline & Clinical Response & 9 & 0 \\
\hline & $\begin{array}{l}\text { Total budget according } \\
\text { to clinical response }\end{array}$ & 390.112 .245 & \\
\hline \multirow[t]{4}{*}{ IV } & Progressive & & \\
\hline & Total budget & 2.860 .798 .361 & 3.145 .145 .914 \\
\hline & Clinical response & 1 & 3 \\
\hline & $\begin{array}{l}\text { Total budget according } \\
\text { to clinical response }\end{array}$ & 43.345 .805 & 241.934 .301 \\
\hline
\end{tabular}

in chemoradiation therapy has a bigger budget than the progressive report in chemotherapy meaning that chemoradiation is more expensive than chemotherapy with a progressive response.

\section{Sensitivity analysis}

According to Table 2, it is seen through sensitivity analysis, chemotherapy and chemoradiation toward salary, investment, operational, stationery, electricity and any other budgets which are not medical budget. From the CER value, chemotherapy has a higher value in chemoradiation without salary, investment, and maintenance

Table 2: CER simulation budget for each patient in a different modality for treating advance cervical carcinoma according to complete clinical responses

\begin{tabular}{|c|c|c|c|}
\hline \multirow{2}{*}{ No } & \multirow[t]{2}{*}{ Characteristics } & \multicolumn{2}{|c|}{ Modality } \\
\hline & & Chemotherapy & Chemoradiation \\
\hline \multirow[t]{2}{*}{1} & Complete CER & 1.647 .140 .590 & 2.419 .343 .010 \\
\hline & & 100 & 100 \\
\hline \multirow[t]{2}{*}{2} & CER without salary & 865.090 .345 & 1.224 .305 .453 \\
\hline & & 52.52 & 50.60 \\
\hline \multirow[t]{2}{*}{3} & $\begin{array}{l}\text { CER without } \\
\text { investment and }\end{array}$ & $862.777 .976,9$ & 1.152 .922 .650 \\
\hline & maintenance budget & 52.38 & 47.65 \\
\hline \multirow[t]{2}{*}{4} & $\begin{array}{l}\text { CER without salary, } \\
\text { investment, and }\end{array}$ & $43.695,2$ & $311.004,6$ \\
\hline & maintenance budget & 0,003 & 0.013 \\
\hline \multirow[t]{2}{*}{5} & $\begin{array}{l}\text { CER without } \\
\text { salary, investment, }\end{array}$ & 43.662 & 310.980 \\
\hline & $\begin{array}{l}\text { operational, and } \\
\text { maintenance budget }\end{array}$ & 0.0027 & 0.013 \\
\hline
\end{tabular}


Table 3: Cost-effectiveness ratio for treating advanced cervical carcinoma according to clinical response inward patients of $\mathrm{Dr} \mathrm{M}$ Hoesin General Hospital, Palembang in 2014

\begin{tabular}{llllll}
\hline \multicolumn{2}{l}{$\begin{array}{l}\text { Therapy } \\
\text { response }\end{array}$} & \multicolumn{2}{c}{ Chemotherapy } & \multicolumn{2}{l}{ Chemoradiation } \\
\cline { 2 - 5 } Response & Budget & CER & Budget & CER \\
\hline 1 Complete & 1647140590 & 1.7 & 2419343010 & 1.3 \\
2 & Partial & 780224490 & 18 & 483868602 & 6 \\
3 & No response & 390112245 & 7.3 & 0 & \\
4 & Progressive & 43345805 & 65 & 241934301 & 13 \\
& & & 31451459143 & \\
& Total & 2860798361 & & 3145145914 & \\
\hline
\end{tabular}

budget. It means that it is more effective to give chemoradiation. If only CER value for chemotherapy is smaller without salary, investment, operational, and maintenance budget then chemotherapy would be the most sensitive one. This study will show the effective budget ratio between advanced cervical carcinoma alternatives, chemoradiation compared with chemotherapy.

It is seen in Table 3 that complete clinical response in treating advanced cervical carcinoma by chemoradiation has lower CER value than chemotherapy has 1.3 and 1.7, respectively. It means that chemoradiation is more effective than chemotherapy for treating advanced cervical carcinoma according to clinical response inward patients at general hospital of Dr M Hoesin, Palembang in 2014. The similar one could be found in partial and progressive clinical response.

\section{DISCUSSION}

The aim of this research is to know the alternative modalities used for treating advanced cervical carcinoma with the most cost-effective and efficient budgets. Because of that, the total budget of each modality (chemotherapy and chemoradiation) will be assessed. Drummond et al. stated bravely that analysis should contain the total cost for medical and nonmedical services and the advantage of this must be separately analyzed to get the cost for clear medical planning. ${ }^{12-13}$

By knowing the total budget for advanced cervical carcinoma management then it will be known the causal of high or low budget for each modality and that would be the preference to determine the most cost-effective therapy so that the hospital could do controlling budget and prevent the lost money. This study also needs to find out whether the cheaper modality (chemotherapy) will give a similar effectiveness of therapy output. It is true that the budget for each patient in chemoradiation management is higher than in chemotherapy management, but it is because of the more expensive device investment for radiation than for chemotherapy that is why the effective ratio should be counted. Marino et al. sug- gested that assessing the budget between conventional laparoscopic and robotic in gynecology carcinoma cases showed that there is a significant difference between the price of robotic and conventional. Robotic management spent much more money for investment and maintenance budget than the conventional one. ${ }^{14}$

The successful treatment for carcinoma is reached if patients achieved complete or partial clinical response while no response and progressive response are the signs of bad treatment, it is obviously seen that CER value for chemoradiation is smaller than for chemotherapy meaning that chemoradiation is more effective for treating advanced cervical carcinoma than chemotherapy.

In conclusion, from all the therapy outputs above, CER is the best indicator in managing the advanced cervical carcinoma in determining whether the modalities have given the most cost-effective budgets compared to the success of clinical response of the therapy. The lower value of CER value, the better choice that modality or the more effective that modality will give in therapy response. ${ }^{12,13}$

According to the CER (Tables 2 and 3), it is known that the more effective modality for treating advanced cervical carcinoma is chemoradiation and when it comes to drug analysis then it will present the most cost-effective budget of the drug so that it would increase the efficiency and the effective value for the sake of the hospital. O'Reilly et al. suggested that there will be two primary approaches for economic evaluation according to trial and model. There are three types of evaluation that could be considered for giving information related to determining the best medical services namely budgets of cost-effectiveness, cost-utility and cost-benefit analyses. ${ }^{15}$

Phippen et al. assessed that cost-effectiveness in treating advanced cervical carcinoma between concurrent gemcitabine and cisplatin followed by adjuvant gemcitabine and cisplatin compared to standard therapy for chemoradiation with cisplatin 41.33 dollars and 60.9 dollars gemcitabine and the costeffectiveness ratio are 50 and 100 . Chemoradiation with gemcitabine and cisplatin followed by two cyclus of adjuvant gemcitabine with cisplatin are more effective than chemoradiation standard only with cisplatin. ${ }^{16}$ Smith et al. through his assessment towards costeffectiveness of "progression-free survival" concurrent gemcitabine and cisplatin with radiation and followed by gemcitabine and cisplatin adjuvant (RT/GC + GC) compared with cisplatin chemoradiation (RT/C) and the result is "cost-effectiveness ratio" between RT/GC + GC is higher than RT/C namely 28,637 and 26,853 respectively, and he concluded that RT/GC+GC is less "cost-effectiveness". ${ }^{17}$ 
When choosing the treatment for carcinoma patient, it is an important thing to consider several criteria to analyze the effectiveness and best cost comparison for the limited facilities and budget through identifying the therapy output of the patient. According to this consideration, chemoradiation would be the best choice. Perri et al. on his research stated that deferring the primary treatment in cervical carcinoma patient because of conserving the fertility or ovarian function, in fact, it does not affect significantly the survival rate of patients and this matters influenced by several factors such as stage, histopathological result, and involvement of lymphadenopathy. ${ }^{18}$ Chemotherapy as primary therapy in advanced cervical carcinoma of Dr M Hoesin General Hospital, Palembang is emerged because of facilities limitation that pushes patients to wait for a long time period before they got chemoradiation.

Just because Perri et al. research resulted in the most effective management is chemoradiation, then patients of Dr M Hoesin General Hospital, Palembang will still undergo the chemoradiation treatment even they have to wait for the schedule. ${ }^{18}$ Meanwhile, Hoch et al. stated based on his research that clinician must be certain for the importance of therapy output by not leaving the economic evaluation, in fact, the new treatment could have the more expensive or more effective in terms of cost of therapy. ${ }^{19}$

\section{CONCLUSION}

It can be concluded that chemoradiation therapy is more cost-effective than chemotherapy because the CER value of chemoradiation is lower than of chemotherapy for patients treated at Dr M Hoesin General Hospital Palembang.

\section{REFERENCES}

1. World Health Organization. International Agency for Research on Cancer. Press Release N 223. 12 December 2013

2. Ferlay J, Shin HR, et al. GLOBOCAN 2008, cancer incidence and mortality Worldwide: IARC Cancer Base No. 10. Lyon, France. International Agency for Research on Cancer; 2010. Search Google Scholar. Available at: http://globocan.iarc.fr. Accessed: September 1, 2014

3. National Comprehensive Cancer Network. NCCN clinical practice guidelines in oncology: cervical cancer. National Comprehensive Cancer Network, Inc. 2006.
4. Drummond M, Stoddart GL, et al. Methods for the Economic Evaluation of Health care Programmes. Toronto: Oxford University Press; 1988

5. Haycox A. What is health economics?. Second Edition; 2009. Page 1-8. Liverpool: Hayward medical Pub Supprted by Sanofi-aventis. Available at: RSUP Dr. M. Hoesin Palembang. whatisseries.co.uk. Accessed: September 1, 2014

6. Neumann PJ. Costing and Perspective in Published CostEffectiveness Analysis. Med Care 2009;47:S28-S32

7. Robinson R. Economic Evaluation and Health Care. What does it mean? BMJ 1993;307:60-63

8. Sorenson C, Tarricone R, et al. Applying health economics for policy decision making: do devices differ from drugs? Europace 2011;13:ii54-ii58.

9. Chaikledkaew U, Teerawattananon. Presentatin of economic evaluation results. J Med Assoc Thai 2008;91(Suppl 2):66-73.

10. Scandurra G, Scibilia G, et al. Efficacy and tolerability of paclitaxel, ifosfamide, and cisplatin as a neoadjuvant chemotherapy in locally advanced cervical carcinoma. J Gynecol Oncol 2015;26(2):118-124.

11. Miše BP, Jelavic TB, et al. Long follow-up of patients with locally advanced cervical cancer treated with concomitant chemo-brachyradiotherapy with cisplatin and ifosfamide followed by consolidation chemotherapy. In Int J Gynecol Cancer 2015; 25: 315-319.

12. Drummond M. Experimental versus observational data in the economic evaluation of pharmaceuticals. Med Care 1988;2: S12-S17.

13. Drummond M, Sculpher M. Common Methodological Flaws in Economic Evaluations. Med Care 2005;43:II-5-II-14.

14. Marino P, Houvenaeghel G, et al. Cost effectiveness of conventional vs robotic-assisted laparoscopy in gynecologic indication. Int J Gynecol Cancer 2015;25:1102-1108.

15. O'Reilly D, Gaebel K, et al. Health economic evaluations help inform payers of the best use of scarce health care resources. Int J Circumpolar Health 2011;4:419-427.

16. Phippen NT, Leath III CA, et al. Cost effectiveness of concurrent gemcitabine and cisplatin with radiation followed by adjuvant gemcitabine and cisplatin in patients with stages IIB to IVA carcinoma of the cervix. Gynecol Oncol 2012; 127: 267-272.

17. Smith B, Cohn DE, et al. Is the progression free survival advantage of concurrent gem-citabine plus cisplatin and radiation followed by adjuvant gemcitabine and cisplatin in patients with advanced cervical cancer worth the additional cost? A cost-effectiveness analysis. Gyn Onc 2013;130:416-420.

18. Perri $T$, Issakov G, et al. Effect of treatment delay on survival in patients with cervical cancer a historical cohort study. Int J Gynecol Cancer 2014;24:1326-1332.

19. Hoch JS, Dewa CS. An Introduction to economic evaluation: What's in a name?. Can J Psychiatry 2005;50(3):159166. 